\title{
The Regulatory Connection between the Activity of Granule Cell NMDA Receptors and Dendritic Differentiation of Cerebellar Purkinje Cells
}

\author{
Hirokazu Hirai and Thomas Launey \\ Laboratory for Memory and Learning, RIKEN Brain Science Institute, Saitama 351-0198, Japan
}

It is known that cerebellar granule cells are powerful inducers for the differentiation of Purkinje cells. However, the detailed mechanism of this regulation has not yet been clarified. Here, using cerebellar neuronal culture, we show that the activation of NMDA receptors expressed by granule cells triggers the signaling pathway for the dendritic differentiation of Purkinje cells. This signal has been shown to promote the granule cell survival through BDNF-mediated TrkB activation, leading to Purkinje cell differentiation by increasing the granule-Purkinje cell interaction. Among the possible signal molecules provided to the dendrites of Purkinje cells from granule cells, nitric oxide was found to have no effect on the dendritic outgrowth and branching, but electrical activity and the subsequent intracellular $\mathrm{Ca}^{2+}$ increase were thought to play an important role in the branching and thickening of the dendrites, because blockade of both non-NMDA and metabotropic glutamate receptors caused a significant decrease in the number of branch points and the diameter of Purkinje dendrites without apparently affecting the dendrite extension and spine formation. Collectively, these results suggest that Purkinje cell differentiation is regulated by two successive steps. The first step is initiated by the NMDA receptor-mediated signal in granule cells, which acts as a trophic factor for granule cells. The second step involves the activation of granule-Purkinje synapses, providing neurotrophic substances and electrical activity essential for Purkinje cell differentiation.

Key words: Purkinje cell; granule cell; NMDA receptor; BDNF; TrkB; development
As the only outputs of the cerebellar cortex, Purkinje neurons are suggested to play an important role in movement coordination and motor learning (Ito, 1984). For the differentiation and maturation of Purkinje cells, in addition to genetic regulations, local epigenetic factors released from granule cells are thought to be essential because Purkinje cells cultured alone develop only poor dendritic arborization with primitive spines, whereas coculture of Purkinje cells with granule cells results in well differentiated dendrites studded with mature spines (Baptista et al., 1994; Morrison and Mason, 1998). However, the details of the mechanisms regulating Purkinje cell differentiation have not yet been clarified.

Neurotrophins are a family of structurally and functionally related peptide growth factors, including neurotrophin-3 (NT-3), NT-4/5, nerve growth factor, and brain-derived neurotrophic factor (BDNF). They play important roles in neuronal proliferation, development, and maturation during neurogenesis (Mount et al., 1994; Gao et al., 1995; Snider and Lichtman, 1996). The biological activities of neurotrophins are mediated by Trk receptors, which are members of the tyrosine kinase receptor family (Chao, 1992). Cerebellar granule cells, which synthesize neurotrophins (Rocamora et al., 1993), express their receptors (Schwartz et al., 1997) and are responsive to neurotrophins (Segal et al., 1992, 1995; Gao et al., 1995). Accumulating evidence revealed that stimulation of NMDA receptors on granule cells induces the synthesis and release of BDNF and, consequently, promotes survival and differentiation of granule cells (Moran and Patel, 1989; Burgoyne et al., 1993; Marini et al., 1998). Together with the evidence that granule cells induce differentiation of Purkinje dendrites, these results suggest that activation of NMDA receptors on granule cells may play a crucial role in differentiation of Purkinje cells via increase in

Received Nov. 11, 1999; revised April 24, 2000; accepted April 25, 2000.

We thank Prof. Masao Ito for his encouragement and the use of his laboratory in which these experiments were performed. We also thank Dr. S. Furuya for teaching the techniques of Purkinje cell culture and T. Torashima for expert technical assistance.

Correspondence should be addressed to Dr. H. Hirai at the Laboratory for Memory and Learning, RIKEN Brain Science Institute, Wako, Saitama 351-0198, Japan. E-mail: hirai@postman.riken.go.jp.

Copyright (C) 2000 Society for Neuroscience $0270-6474 / 00 / 205217-08 \$ 15.00 / 0$ the trophic influence of granule cells. In this study, using cocultures of Purkinje cells and granule cells, we demonstrate a regulatory connection between the activation of granule cell NMDA receptors and the dendritic differentiation of Purkinje cells. We further examined the nature of this trophic effect through electrical activity or release of substances, such as neurotrophins or nitric oxide (NO).

\section{MATERIALS AND METHODS}

Cerebellar neuronal culture. Dissociated cerebellar neuronal cultures were prepared from the brains of 20- to 21-d-old Wistar rat fetuses according to a recently published protocol for Purkinje cell culture (Furuya et al., 1998) with slight modifications. In brief, $5.0 \times 10^{6} \mathrm{cells} / \mathrm{ml}(200,000$ cells per well in $40 \mu \mathrm{l})$ were plated onto plastic coverslips $(21 \mathrm{~mm}$ in diameter; Sumilon MS-80060; Sumitomo Bakelite, Tokyo, Japan) coated with poly-Lornithine and placed in a humidified $\mathrm{CO}_{2}$ incubator $\left(5 \% \mathrm{CO}_{2}\right.$ at $\left.37^{\circ} \mathrm{C}\right)$. This culture contained $\sim 70 \%$ of neuron-specific enolase (NSE)-positive cells. All other cells were glial fibrillary acidic protein-positive. The ratio of granule cells to Purkinje cells was $\sim 20: 1$. One milliliter of serum-free culture medium was added to each well after $3 \mathrm{hr}$. The medium was composed of DMEM-nutrient mixture of Ham's F-12 supplemented with bovine insulin $(10 \mu \mathrm{g} / \mathrm{ml})$, bovine serum albumin $(100 \mu \mathrm{g} / \mathrm{ml})$, gentamicin $(5 \mu \mathrm{g} / \mathrm{ml})$, glutamine $(200 \mu \mathrm{g} / \mathrm{ml})$, human apotransferrin $(100 \mu \mathrm{g} / \mathrm{ml})$, progesterone $(40 \mathrm{nM})$, putrescine $(100 \mathrm{nM})$, sodium selenite $(30 \mathrm{~nm})$, and triiodothyronine $(0.5 \mathrm{ng} / \mathrm{ml})$.

Antisense oligonucleotide treatment. The cerebellar neuronal cultures were treated with 1 or $0.5 \mu \mathrm{M}$ oligonucleotide throughout the cultivation period. Half of the culture medium was replaced every second day with fresh medium containing $1 \mu \mathrm{M}$ oligonucleotide. The oligonucleotide was designed to encompass the initiative methionine codon of NR2D subunit. For controls, the sense and a missense oligonucleotides were used. The sequences of 25 -mer sense, antisense, and missense oligonucleotides were $5^{\prime}$-aagcttcttagaccatgagaggagc- $3^{\prime}, \quad 5^{\prime}$-gctcctctcatggtctaagaagctt-3', and 5'agaagtgccgttggcatatcaaagt- $3^{\prime}$, respectively.

Electrophysiology. The experiments were performed on cultures at 7-20 $\mathrm{d}$ in vitro (DIV). The recording chamber was clamped on the stage of a Nikon (Tokyo, Japan) TE300 inverted microscope and observed with phase contrast optics. The preparation was continuously superfused with an extracellular solution containing (in $\mathrm{mm}$ ): $\mathrm{NaCl} 140, \mathrm{KCl} 3, \mathrm{CaCl}_{2} 3$, glucose 10, HEPES 10 , pyruvic acid 3 , picrotoxin 0.03 , glycine 0.01 , and tetrodotoxin (TTX) $0.5 \mu \mathrm{M}, \mathrm{pH} 7.35$ (330 mOsm $\left./ \mathrm{kg}, 31^{\circ} \mathrm{C}\right)$. Whole-cell voltage-clamp recordings were made from visually identified Purkinje cells. Patch pipettes were pulled from borosilicate glass capillaries $(1.5 \mathrm{~mm}$ outer diameter, $0.86 \mathrm{~mm}$ inner diameter; Clark Biomedical Instruments, Panbourne, UK) and fire-polished to achieve a resistance of 3-6 $\mathrm{M} \Omega$ when filled with a solution containing (in $\mathrm{mM}$ ): $\mathrm{K}$ gluconate $60, \mathrm{~K}$ methanesulfonate $60, \mathrm{KCl} 20,6 \mathrm{H}_{2} \mathrm{O} \cdot \mathrm{MgCl}_{2} 0.5, \mathrm{Na}_{2}$ ATP 4.0, $\mathrm{Na}_{2}$ GTP 0.2, HEPES 
30, EGTA 10, $\mathrm{CaCl}_{2}$ 0.8, and reduced glutathione 1.0, pH 7.4 (310 $\mathrm{mOsm} / \mathrm{kg}$ ). The series resistance in the whole-cell configuration was 7-15 $\mathrm{M} \Omega$ and was not compensated. To evoke NMDA receptor-mediated current in voltage-clamped Purkinje cell $(-65 \mathrm{mV})$, a pipette $(0.5-1 \mathrm{M} \Omega)$ containing $500 \mu \mathrm{M}$ NMDA dissolved in extracellular solution was positioned upstream of the soma of the Purkinje neuron. Recordings were made using an Axopatch 1D amplifier (Axon Instruments, Foster City, CA). Signals were filtered at $1 \mathrm{kHz}$ and digitized at $2 \mathrm{kHz}$ (Digidata 1200)

Immunofluorescence. For double immunocytochemical staining, calbindin D-28K and NSE were used as a Purkinje cell-specific marker and a neuronal marker, respectively. A cerebellar culture at 14 DIV was fixed for $2 \mathrm{hr}$ at $4^{\circ} \mathrm{C}$ in $4 \%$ paraformaldehyde in PBS and then blocked with $2 \%$ bovine serum albumin and $0.4 \%$ Triton X-100 in PBS for $30 \mathrm{~min}$. The primary antibodies used were mouse monoclonal anti-calbindin D-28K (1:200; Sigma, St. Louis, MO) and rabbit polyclonal anti-NSE (1:2000 Polysciences, Warrington, PA) antibodies. The cultures were incubated with primary antibodies for $2 \mathrm{hr}$ at room temperature and then incubated with appropriate secondary antibodies for $1 \mathrm{hr}$ at room temperature. Secondary antibodies were conjugated to fluorescein and rhodamine (1: 200; Chemicon, Temecula, CA).

Acquisition and analysis of fluorescent images. Fluorescent images of cerebellar neurons were acquired using a cooled CCD camera (12 bit; SenSys Camera System; Photometrics, Tucson, AZ) attached to a fluorescence microscope (BX60; Olympus Optical, Tokyo, Japan) with a 40× objective (225 pixels $\left./ \mu \mathrm{m}^{2}\right)$. The exposure time was automatically adjusted so that the maximum pixel value was 2048. Images were analyzed using IPLab (Scanalytics Inc., Fairfax, VA) to evaluate the maximum length and number of branch points of the Purkinje cell dendrites. Branch points were counted along the longest dendrite. Unless otherwise indicated, $>30$ Purkinje neurons were analyzed in each experiment. Granule cell survival was estimated by counting the number of calbindin D-28K-negative and NSE-positive cells with diameters of $\sim 5-10 \mu \mathrm{m}$. The number of granule cells was counted in three randomly selected fields in images acquired by the $\mathrm{CCD}$ camera with a $40 \times$ objective $(223 \times 174 \mu \mathrm{m})$. All experiments were performed using cultures from at least three different batches.

Materials. Human recombinant BDNF and NT-3 were obtained from Sigma. Rabbit polyclonal TrkB-IgG and TrkC-IgG were from Transduction Laboratories (Lexington, KY). ( \pm )1-(4-Aminophenyl)-3-methylcarbamyl7,8-methylenedioxy-3,4-dihydro-5H-2,3-benzodiazepine (GYKI 53655) was generously provided by Dr. I. Tarnawa (Gerdeon Richter Ltd., Budapest, Hungary). D(-)-2-Amino-5-phosphonopentanoic acid (APV), NMDA, 6-cyano-7-nitroquinoxaline-2,3-dione (CNQX), (RS)- $\alpha$-methyl-4carboxyphenylglycine (MCPG), $(R S)$-1-aminoindan-1,5-dicarboxylic acid (AIDA), TTX, and $N^{\mathrm{G}}$-nitro-L-arginine methyl ester hydrochloride (LNAME) were from Tocris Cookson (Bristol, UK).

Statistical analysis. Data were expressed as mean $\pm \mathrm{SD}$, unless otherwise indicated. ANOVA with Fisher's least significant difference test was used to evaluate the effects of drug treatments on the survival of granule cells and the dendritic differentiation of Purkinje cells. The Pearson correlation was used to determine the significance of correlations between granule cell density and dendritic outgrowth or branching of Purkinje cells.

\section{RESULTS}

\section{APV, but not CNQX or MCPG, prevents Purkinje cell differentiation}

To examine whether NMDA signals selectively contribute to the development and maturation of Purkinje cells, dissociated cerebellar neurons were grown in the presence of various ionotropic and metabotropic glutamate receptor antagonists for $14 \mathrm{~d}$. Control Purkinje cells grown without any glutamate receptor blockers displayed well differentiated dendrites studded with spines (Fig. 1A). The non-NMDA receptor antagonist CNQX $(10 \mu \mathrm{M})$ and the metabotropic glutamate receptor antagonist MCPG (1 mM) did not markedly affect Purkinje cell morphology (Fig. 1C,D). Quantitative analysis revealed that the dendrites of Purkinje cells cultured with the above-mentioned antagonists were more extended than those of control cells (Table 1). Treatment of Purkinje cells with another metabotropic glutamate receptor antagonist, AIDA, also resulted in similar growth patterns (data not shown). In contrast, the competitive NMDA receptor antagonist APV $(100 \mu \mathrm{M})$ significantly affected the differentiation of Purkinje cells; the dendrites were apparently shorter and less branched. Moreover, the spines were primitive and fewer in number than those formed on the dendritic shafts of control Purkinje cells (Fig. $1 B$, and data not shown). The effects of APV on the differentiation of Purkinje cells were dosedependent (Fig. 2), and the $\mathrm{IC}_{50}$ values with regard to the length of the dendrites and to the number of branch points were $\sim 20$ and 10 $\mu \mathrm{M}$, respectively. The APV-induced reduction of the dendritic differentiation of Purkinje cells could be reversed by coapplication of NMDA at a concentration ranging from 30 to $300 \mu \mathrm{M}$ into the

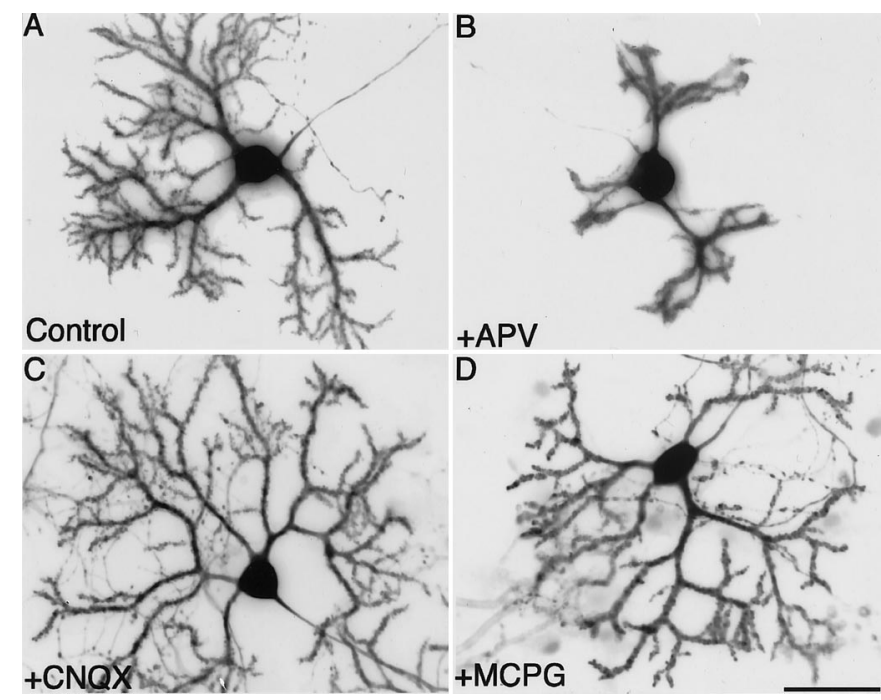

Figure 1. Effects of the blockade of various glutamate receptor subtypes on Purkinje cell differentiation. Primary dissociated cerebellar neurons were cultured in the absence $(A)$ or presence $(B)$ of $100 \mu \mathrm{M} \mathrm{APV}, 10 \mu \mathrm{M}$ CNQX $(C)$, or $1 \mathrm{~mm} \mathrm{MCPG}(D)$. Purkinje cells at 14 DIV were visualized by immunocytochemical staining for calbindin D-28K. Scale bar, $50 \mu \mathrm{m}$.

culture medium (Fig. $3 A a, A b$ ). This suggests that the inhibitory effect of APV on the dendritic differentiation of Purkinje cells was specifically mediated by the blockade of NMDA receptors and not by its toxic action. The addition of NMDA without APV to the cerebellar neuronal culture did not significantly change the dendrite length, but branching of the Purkinje cells was increased by NMDA application at $30 \mu \mathrm{M}$ (Fig. $3 A a, A b$, insets).

\section{Granule cell NMDA receptor activity mainly contributes to the dendritic differentiation of Purkinje cells}

Previous studies have shown that, although adult Purkinje cells do not express functional NMDA receptors, both granule cells and Purkinje cells show NMDA responsiveness at an early stage of development (Kilic et al., 1991; Rosenmund et al., 1992; Yuzaki et al., 1996). To determine which NMDA receptors are involved in Purkinje cell differentiation, we attempted to selectively eliminate the NMDA receptors on Purkinje cells, using antisense approach. Because developing Purkinje cells express only NR2 subunits of the "D" type, whereas granule cells express NR2A, 2B, and 2C but not 2D subunits (Akazawa et al., 1994; Momiyama et al., 1996; Gavin and Stefano, 1999), we used an antisense oligonucleotide selectively directed against the N-terminal part of NR2D. The antisense oligonucleotide-induced suppression of Purkinje cell NMDA receptor activity was verified by electrophysiology (Fig. $4 A$ ). Recording from antisense oligonucleotide-treated Purkinje cells showed an $\sim 90 \%$ reduction in the NMDA-induced current (eight cells), whereas sense oligonucleotide-treated Purkinje cells (three cells) were similar to control (three cells). No difference in the granule cell sensitivity was observed between sense- and antisense-treated conditions (number of granule cells examined; antisense 18 and sense 7). Another antisense oligonucleotide with a similar length, but starting 11 bases upstream of the antisense sequence of NR2D, failed to significantly reduce the NMDA current in the Purkinje cells (five cells tested; data not shown). When experiments were repeated in the presence of $5 \mu \mathrm{M}$ GYKI 53655, a noncompetitive AMPA-type receptor antagonist, similar results were obtained. Morphological studies revealed that Purkinje cells treated with the oligonucleotides exhibited a slight but significant decrease in the length of the dendrites (missense and antisense oligonucleotide-treated cells) and the number of branch points (sense, missense, and antisense oligonucleotide-treated cells), probably attributable to a nonspecific side effect of oligonucleotides (Fig. 4B). However, the effect of the combined application of APV together with the antisense oligonucleotide was much 
Table 1. Effects of glutamate receptor antagonists on the differentiation of Purkinje cells

\begin{tabular}{lllll} 
& $\begin{array}{l}\text { Dendrite } \\
\text { length }(\mu \mathrm{m})\end{array}$ & $\begin{array}{l}\text { Number of branch } \\
\text { points/dendrite }\end{array}$ & $\begin{array}{l}\text { Number of branch } \\
\text { points/100 } \mu \mathrm{m} \text { dendrite }\end{array}$ & $\begin{array}{l}\text { Dendrite } \\
\text { thickness }(\mu \mathrm{m})\end{array}$ \\
\hline Control & $129 \pm 16.2$ & $10.9 \pm 2.27$ & $8.45 \pm 1.76$ & $4.43 \pm 0.61$ \\
CNQX & $157 \pm 22.2^{* *}$ & $11.0 \pm 2.33$ & $7.01 \pm 1.48^{* *}$ & $4.61 \pm 0.76$ \\
MCPG & $154 \pm 19.6^{* *}$ & $12.0 \pm 3.31$ & $7.79 \pm 2.14$ & 78 \\
CNQX plus MCPG & $118 \pm 15.9$ & $7.47 \pm 1.50^{* *}$ & $6.33 \pm 1.27^{* *}$ & $89 \pm 0.87$ \\
CNQX plus MCPG plus KCl & $152 \pm 25.0^{* *}$ & $12.4 \pm 3.13$ & $8.15 \pm 2.06$ & $3.15 \pm 0.56^{* *}$ \\
\end{tabular}

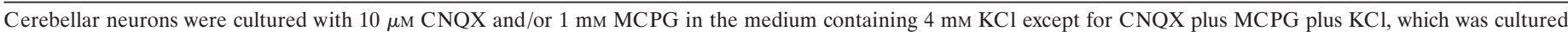

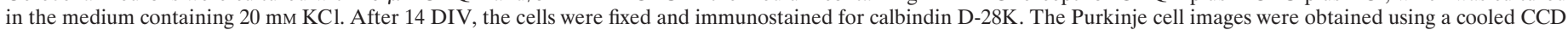

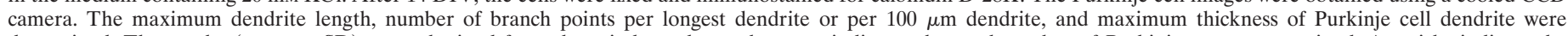

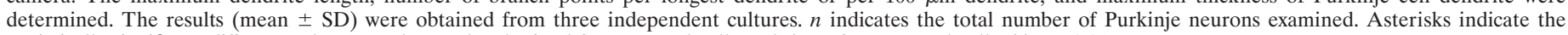
statistically significant differences between the results obtained from control cells and those from treated cells; $* * p<0.01$.

A +APV
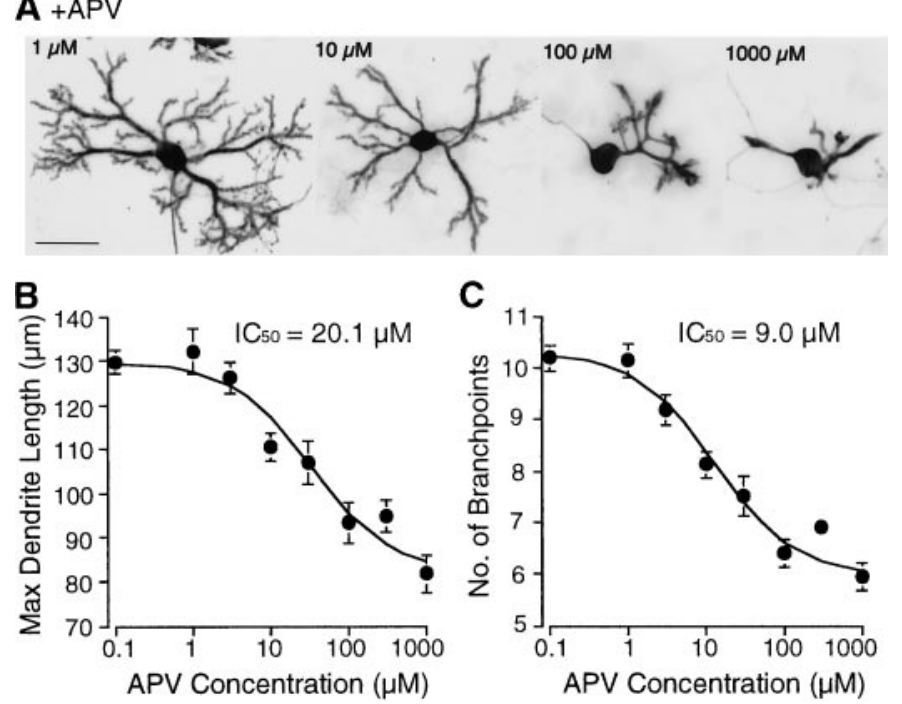

Figure 2. Dose-response relationship between concentration of APV in the culture medium and differentiation of Purkinje cells. Cerebellar neurons were cultured in the presence of various concentrations of APV. At 14 DIV, Purkinje cells were immunostained for calbindin D-28K. Images of Purkinje cells were obtained using a CCD camera. $A$ shows representative example of Purkinje cells cultured with various concentrations of APV. $B$ and $C$ show the relationship between concentration of APV and maximum dendrite length or the number of branch points per longest dendrite in Purkinje cells, respectively. Data are means of experiments performed in triplicate; $>30$ neurons for each concentration were analyzed. Error bars indicate SEM. Scale bar, $50 \mu \mathrm{m}$.

more severe. The dendrite outgrowth and branching of Purkinje cells were drastically inhibited (Fig. 4B). These results suggest that NMDA receptors on granule cells exert a major influence on the dendritic differentiation of Purkinje cells, although a minor involvement of the NMDA receptors transiently expressed on Purkinje cells cannot be ruled out.

\section{Granule cell density regulates the Purkinje cell differentiation}

Several reports have shown that chronic exposure to NMDA promotes neurite growth, differentiation, and survival of developing granule cells (Balázs et al., 1989; Moran and Patel, 1989; Burgoyne et al., 1993). These findings suggest that NMDA acts as a neurotrophic factor to granule cells and hence blockade of granule cell NMDA receptors by APV decreased the granule cell number, which might indirectly result in the inhibition of Purkinje cell differentiation. This hypothesis is supported by evidence that the cultivation of Purkinje cells without granule cells results in arrested dendritic differentiation (Baptista et al., 1994; Morrison and Mason, 1998). Therefore, we examined whether modulation of NMDA receptor activity regulates the granule cell number by culturing the cells with NMDA and/or APV. At 14 DIV, the cells were fixed and immunolabeled for calbindin D-28K and NSE. Enolase-positive and calbindin-negative cells with diameters of $\sim 5-10 \mu \mathrm{m}$ were identified as granule cells and counted in three randomly selected fields $(223 \times 174 \mu \mathrm{m})$. The results showed that, in the presence of $100 \mu \mathrm{M} \mathrm{APV}$, the survival rate of granule cells was markedly decreased from $\sim 300$ to 140 cells per field (Fig. 3Ac), which was rescued by coincubation with $300 \mu \mathrm{M}$ NMDA. At this concentration of NMDA, a higher survival rate of granule cells was observed even in the presence of APV ( $\sim 450$ cells per field $)$ than that of the control culture $(\sim 300$ cells per field $)$. In the absence of APV, chronic exposure to $30 \mu \mathrm{M}$ NMDA significantly increased the number of granule cells but not that to $300 \mu \mathrm{M}$ NMDA (Fig. $3 A c$, inset). The absence of the trophic effect at $300 \mu \mathrm{M}$ NMDA is probably attributable to $\mathrm{Ca}^{2+}$ toxicity resulting from overstimulation of NMDA receptors. Subsequently, the dose-response relationship of APV on the survival of granule cells was established (Fig. $3 \mathrm{Ba}$ ). As the concentration of APV increases, the survival rate of granule cells decreased with an $\mathrm{IC}_{50}$ value of $5.5 \mu \mathrm{M}$, which is almost identical to the $\mathrm{IC}_{50}$ of $\mathrm{APV}(4.7 \mu \mathrm{M})$ for NMDA-induced current elicited from recombinantly expressed NMDA receptors (Laube et al., 1997). Furthermore, statistical analysis indicated a correlation between granule cell number and maximum dendrite length or number of branch points/longest dendrite of a Purkinje cell (Fig. $3 B b, B c$ ). These results suggest that NMDA receptor signaling in granule cells regulates Purkinje cell differentiation by controlling the survival of granule cells.

\section{TrkB, but not TrkC, signaling mediates Purkinje cell differentiation}

Because NMDA receptor activation has been demonstrated to initiate the synthesis and release of BDNF in granule cells (Favaron et al., 1993; Marini et al., 1998), we hypothesized that blockade of NMDA receptors by APV caused granule cell death because of the inhibition of BDNF release, thereby resulting in the failure of Purkinje cell differentiation. To verify this possibility, we tested whether exogenous application of BDNF into the culture medium could reverse the effects of APV on granule cells and consequently allow Purkinje cell differentiation. The cerebellar neurons were incubated with BDNF at the concentration range of 1-100 ng/ml in the presence or absence of $100 \mu \mathrm{M}$ APV and then fixed and immunostained for calbindin D-28K and NSE. As shown in Figure $5 A$, BDNF application to the cerebellar neuronal culture together with $100 \mu \mathrm{M}$ APV restored the survival rate of granule cells, as well as promoted outgrowth and arborization of the Purkinje cell dendrites in a dose-dependent manner, although cultivation of the cells with BDNF in the absence of APV did not significantly affect those parameters (Fig. $5 B$ ). In contrast, application of TrkB-IgG, which binds to TrkB and blocks the effects of BDNF (Ghosh et al., 1994), resulted in Purkinje cells showing only rudimentary dendrites, as well as increased granule cell death (Fig. 6). Treatment of the culture with a similarly prepared fusion protein, TrkC-IgG, had no significant effects. In addition, the effects of TrkB-IgG was reversed by coapplication of $100 \mathrm{ng} / \mathrm{ml}$ BDNF, suggesting the specificity of TrkB-IgG to the TrkB receptors. 

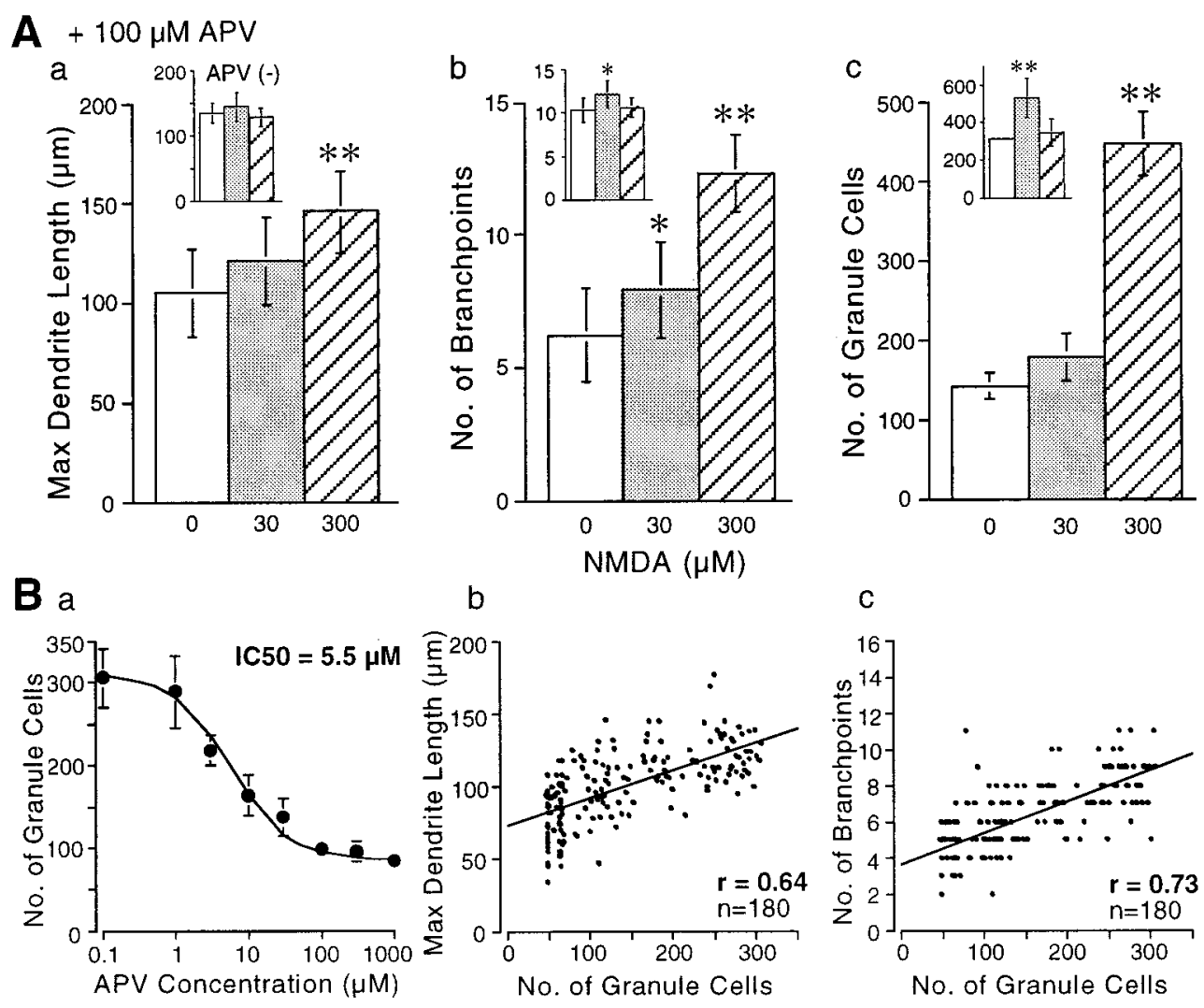

b
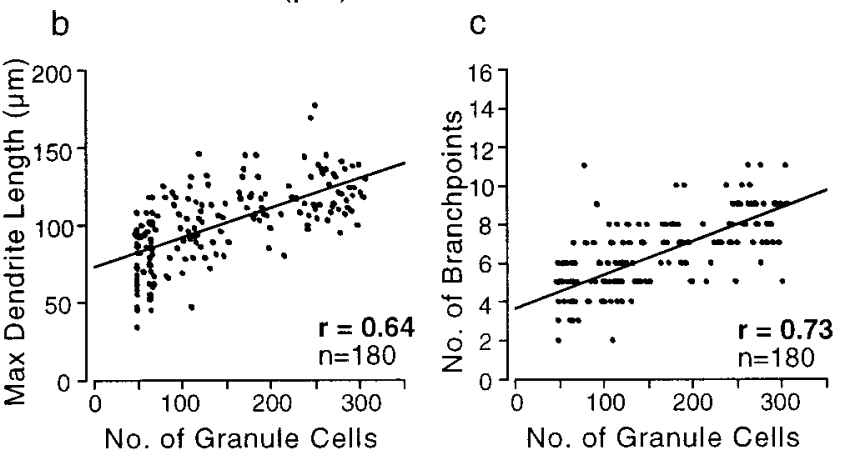

Figure 3. The regulation of granule cell survival and dendritic differentiation in Purkinje cells by NMDA receptor activity. The cerebellar neurons were cultured in medium containing $100 \mu \mathrm{M}$ APV together with 0,30 , or $300 \mu \mathrm{M}$ NMDA $(A)$. After 14 DIV, cells were fixed and immunostained for calbindin D-28K and NSE, followed by the determination of the maximum length of Purkinje dendrites $(a)$, the number of branch points per longest dendrite $(b)$, and the number of granule cells $(c)$. In $a$ and $b,>30$ Purkinje cells were analyzed for each concentration. In $c$, the granule cells were identified as calbindin D-28K-negative and NSE-positive cells with diameters of $\sim 5-10 \mu \mathrm{m}$ and counted for each concentration of NMDA in three randomly selected fields $(223 \times 174 \mu \mathrm{m})$. Insets show the results of similar analysis obtained from the preparations grown without APV. Data are means of experiments performed in triplicate. Error bars indicate SD. Asterisks indicate statistically significant differences from the results of the cultures grown without NMDA; ${ }^{*} p<0.05$, ${ }^{* *} p<0.01$. $B$ shows the correlation of granule cell density with dendritic extension and branching of Purkinje cells. The cerebellar neurons that survived for 14 DIV in the presence of various concentrations of APV were double immunostained for calbindin D-28K and NSE. The number of granule cells was counted in nine randomly selected field positions in three independent cultures and plotted on the graph $(a)$. Error bars indicate SEM. $b$ and $c$ indicate the number of granule cells plotted against the maximum length of the dendrites or the number of branch points per longest dendrite in Purkinje cells. There are significant correlations between these parameters $(p<0.001)$.

Because it has been shown that the TrkC receptor is expressed on both granule and Purkinje cells (Segal et al., 1995; Velier et al., 1997) and that NT-3 promotes the differentiation of both neurons (Lindholm et al., 1993; Segal et al., 1995), we examined whether coapplication of NT-3 with APV could improve Purkinje cell differentiation. However, the addition of NT-3 $(30 \mathrm{ng} / \mathrm{ml})$ alone or together with APV to the cerebellar neuronal culture did not alter dendritic arborization of the Purkinje cells (Fig. 7). Collectively, these observations strongly suggest that the activation of NMDA receptors on granule cells results in the release of BDNF, which promotes granule cell survival through the TrkB signaling pathway, and indirectly leads to Purkinje cell differentiation by enhancing the interaction between the granule cells and Purkinje cells.

\section{Intracellular concentration of $\mathrm{Ca}^{2+}\left(\left[\mathrm{Ca}^{2+}\right]_{\mathrm{i}}\right)$ in Purkinje cells after the synaptic activity is crucial for Purkinje cell dendritic branching}

As possible trophic factors for Purkinje cell differentiation that are released from granule cells, the following substances are speculated: (1) glutamate, as the neurotransmitter at the synapses between these neurons, (2) neurotrophins, and (3) nitric oxide. Although the blockade of AMPA-type or metabotropic glutamate receptors did not inhibit dendritic arborization of Purkinje cells (Fig. 1), blockade of one type of receptor may have been compensated by the activity of another type of receptor. To test this possibility, activation of both AMPA receptors and metabotropic glutamate receptors was blocked by culturing the cells in the presence of $10 \mu \mathrm{M}$ CNQX and $1 \mathrm{~mm}$ MCPG. The cells were fixed at 14 DIV and immunolabeled for calbindin D-28K and NSE. Statistical analysis of Purkinje cell dendritic differentiation shows that, although the length of the dendrites and spine formation were not affected, this treatment resulted in a marked decrease in the number of branch points and diameter of Purkinje cell dendrites (Fig. 8, Table 1). These changes cannot be attributed to a decrease in granule cell survival rate, because the density of granule cells was not significantly decreased (control, $320 \pm 15$ cells per field; CNQX plus MCPG, $310 \pm 18$ cells per field). These results suggest that elevation of the $\left[\mathrm{Ca}^{2+}\right]_{i}$, in response to AMPA-type or metabotropic glutamate receptor activation, might be necessary for dendritic branching, as suggested previously (Spitzer, 1994). Therefore, we next tested whether increasing $\mathrm{Ca}^{2+}$ entry by elevating potassium concentration in the medium prevented the inhibition of branching by the blockade of glutamate receptors. The cerebellar neurons were cultured for 2 weeks in the presence of CNQX, MCPG, and $20 \mathrm{~mm} \mathrm{KCl}$ in the culture medium. At 14 $\mathrm{DIV}$, the cells were immunostained and their dendritic differentiation was evaluated. The sustained depolarization induced by $\mathrm{KCl}$ almost completely counteracted the effects of the ionotropic and metabotropic glutamate receptor antagonists, and the Purkinje cells exhibited well differentiated dendrites similar to those of control cells (Fig. 7, Table 1). Thus, the increase in cytoplasmic $\mathrm{Ca}^{2+}$ accumulation in Purkinje cells seems to play an important role in the growth and branching of the dendrites. 
A
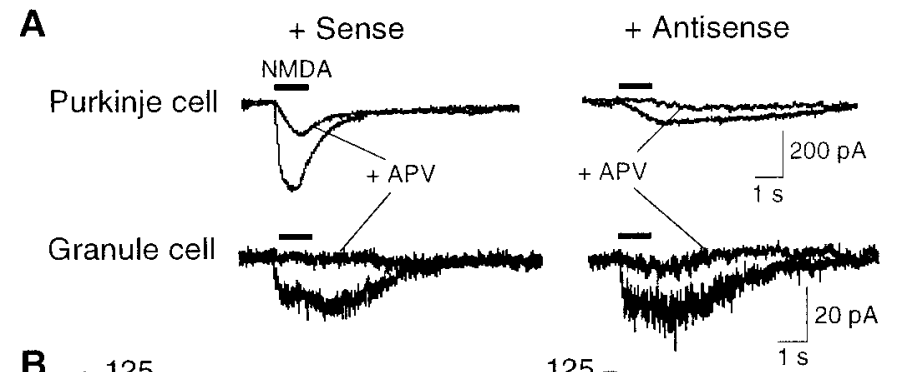

B
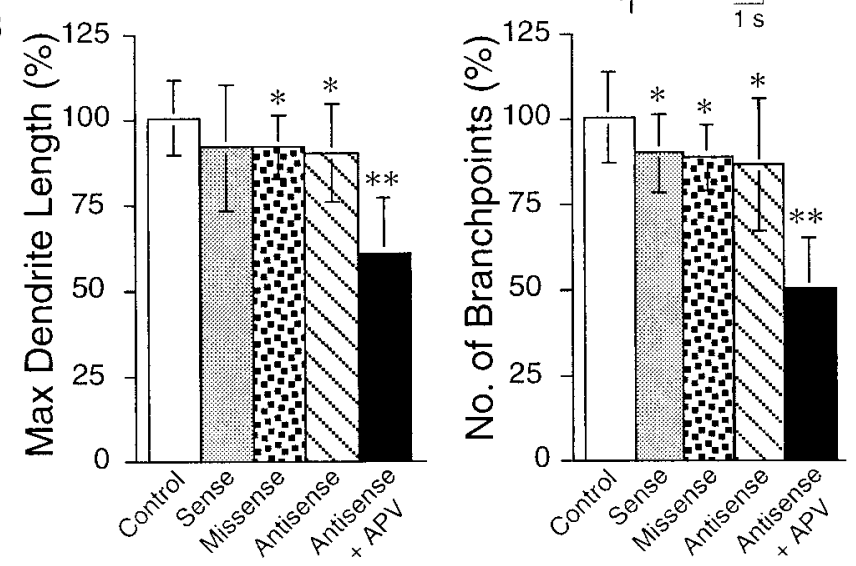

Figure 4. Antisense-mediated suppression of NMDA receptor function in Purkinje cells and its effect on the Purkinje cell differentiation. $A$ shows the NMDA-induced whole-cell currents recorded from Purkinje cells and granule cells treated with a sense oligonucleotide and an antisense oligonucleotide as indicated. Upon application of APV $(50 \mu \mathrm{M})$, the NMDA-induced inward current was considerably decreased in Purkinje cells. $B$ shows the quantitative analysis of Purkinje cell dendritic morphology treated with sense, missense, or antisense oligonucleotides or APV together with the antisense oligonucleotide. In control experiments, the culture was subjected to medium change only. Error bars indicate SD. Asterisks indicate statistically significant differences from the control culture; ${ }^{*} p<0.05,{ }^{*} p<0.01$.

\section{NO signaling is not involved in Purkinje cell differentiation}

Previous reports have shown that the granule cells express NO synthase (NOS) (Schilling et al., 1994) and produce NO mainly in response to NMDA receptor activation triggered by spontaneous synaptic activity, in both cell cultures (Schilling et al., 1994) and cerebellar slices (Southam et al., 1991). In addition, a relationship between NO production and the differentiation of the granule cells has been suggested because the period of the granule cell differentiation was shown to correspond to that of a marked increase in NOS activity and NO formation in the granule cells (Viani et al., 1997). Therefore, the reduced degree of Purkinje cell differentiation by APV may result directly or indirectly from a decrease in NO release by granule cells. To examine this, we inhibited NO production in the cerebellar neuronal culture throughout the cultivation period by adding L-NAME $(5 \mu \mathrm{M})$, a highly potent NOS inhibitor (Pfeiffer et al., 1996). This treatment did not affect granule cell survival or Purkinje cell differentiation as estimated based on the growth and branching of the dendrites $(104.5 \pm 8.4,96.3 \pm 11.0$, and $98.3 \pm 17.9 \%$ of the control level, respectively), suggesting that NO has no apparent effect on the differentiation of Purkinje cells in our culture system.

\section{DISCUSSION}

In the present series of experiments, we show the significant effect of granule cell NMDA receptor activity for Purkinje cell dendritic differentiation. This differentiation effect is mediated by stimulating the BDNF-TrkB signaling pathway in granule cells, resulting in increased survival rate of granule cells, which in turn exerts a trophic effect on Purkinje cells. Moreover, the electrical activity followed by the increase of $\left[\mathrm{Ca}^{2+}\right]_{\mathrm{i}}$ in Purkinje cells is suggested to be essential for the dendritic branching of Purkinje cells.
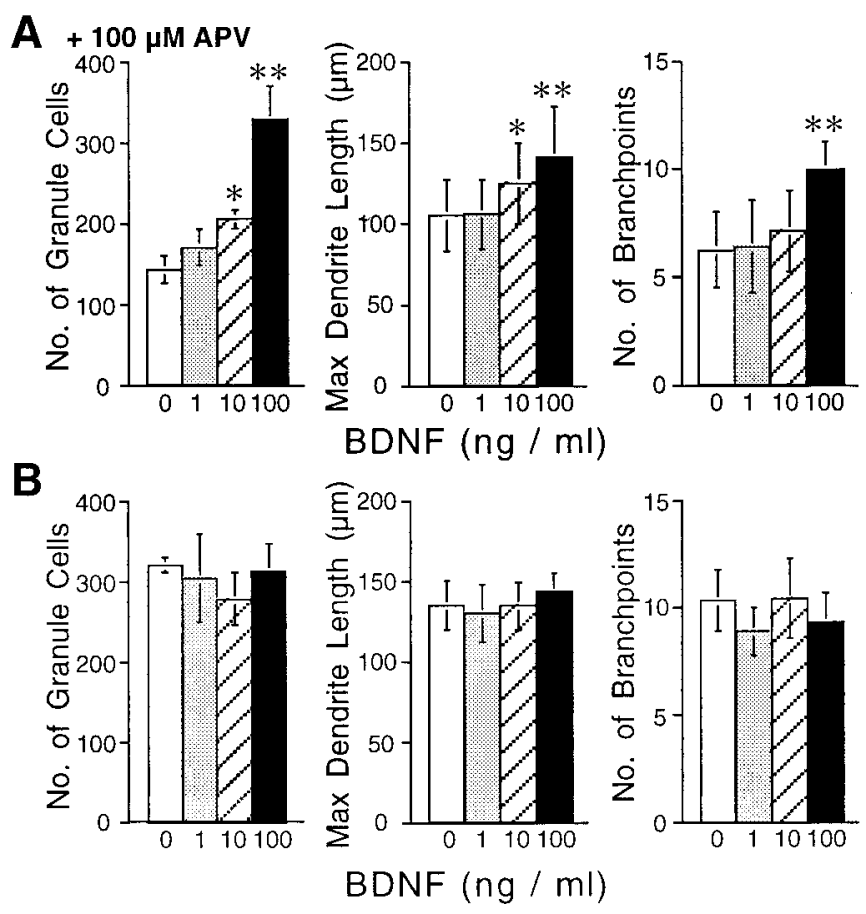

Figure 5. Restoration of dendritic differentiation by BDNF. The cerebellar neurons were cultured in a medium containing $100 \mu \mathrm{M}$ APV in the presence of increasing concentration of BDNF. Neuronal cells fixed at 14 DIV were visualized by double immunocytochemical staining for calbindin D-28K and NSE. The granule cell survival rate, dendritic outgrowth, and branching of Purkinje cells were analyzed for each concentration of BDNF $(A)$. Data are means of experiments performed in triplicate. For each BDNF concentration, $>30$ Purkinje neurons were examined, and granule cells were counted in nine fields. The effects of BDNF without APV are shown in $B$. Error bars indicate SD. Asterisks indicate statistically significant differences from the culture grown without BDNF; ${ }^{*} p<0.05,{ }^{*} p<0.01$.

\section{Activation of the NMDA receptors expressed on granule cells initiates and supports cerebellar neuronal maturation}

Some stimuli that facilitate neuronal differentiation, such as an increase in $\left[\mathrm{Ca}^{2+}\right]_{\mathrm{i}}$ or depolarization, may adversely affect neuronal survival and vice versa. Hence, it would be necessary to discriminate the factors promoting the differentiation from those effective for survival. Moreover, when the effects of some factors on the differentiation of Purkinje cells are examined using the granule cell-Purkinje cell coculture system, one has to consider whether the effects are exerted directly on the Purkinje cells or indirectly through the modulation of afferent neurons, the granule cells. Previous studies have shown that NT-3 (Lindholm et al., 1993) and high potassium levels (Reitstetter and Yool, 1998) promoted the Purkinje cell differentiation and that BDNF (Shimada et al., 1998) increased the spine density on Purkinje dendrites. However, those experiments were performed in coculture with granule cells and therefore, the effects might have been caused indirectly via the modulation of granule cell survival and differentiation because NT-3, BDNF, and high potassium levels have been shown to act as trophic factors for granule cells (Gallo et al., 1987; Gao et al., 1995; Segal et al., 1995). Similarly, our results showing the significant reduction of Purkinje cell dendritic differentiation by the addition of the NMDA receptor antagonist could be explained by the blockade of NMDA receptors on Purkinje cells, which have been shown to be functional during the developmental period (Rosenmund et al., 1992; Yuzaki et al., 1996). To exclude this possibility, we used an antisense technology to examine the effect of the selective suppression of Purkinje cell NMDA receptors on the dendritic differentiation. The major side effect of antisense oligonucleotides is their nonselective hybridization to mRNAs and subsequent suppression of the gene products (Myers and Dean, 2000), which might artifactually affect the Purkinje cell develop- 
A

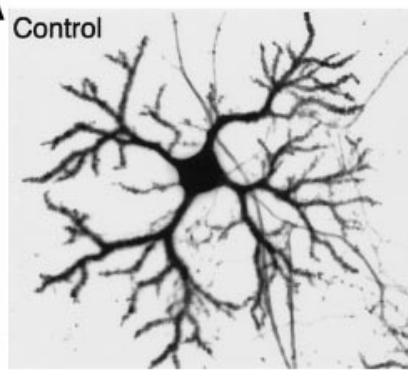

B

Figure 6. Perturbation of the dendritic development of Purkinje cells by blockade of TrkB signaling. Cerebellar neurons were cultured in the presence of TrkB-IgG (final concentration, $25 \mu \mathrm{g} / \mathrm{ml}$ ). The neurons were fixed at 14 DIV and visualized by double immunostaining for calbindin D-28K and NSE. $A$ shows representative examples of Purkinje cells cultured in the absence or presence of TrkB-IgG or TrkB-IgG plus BDNF. $B$ shows the quantitative analysis of the effect of TrkB-IgG, TrkB-IgG plus BDNF, or TrkC-IgG on the granule cell survival and dendritic differentiation of Purkinje cells. Error bars indicate SD. Asterisks indicate statistically significant differences from the untreated control culture; ${ }^{*} p<0.05,{ }^{*} p<0.01$. Scale bar, $50 \mu \mathrm{m}$.
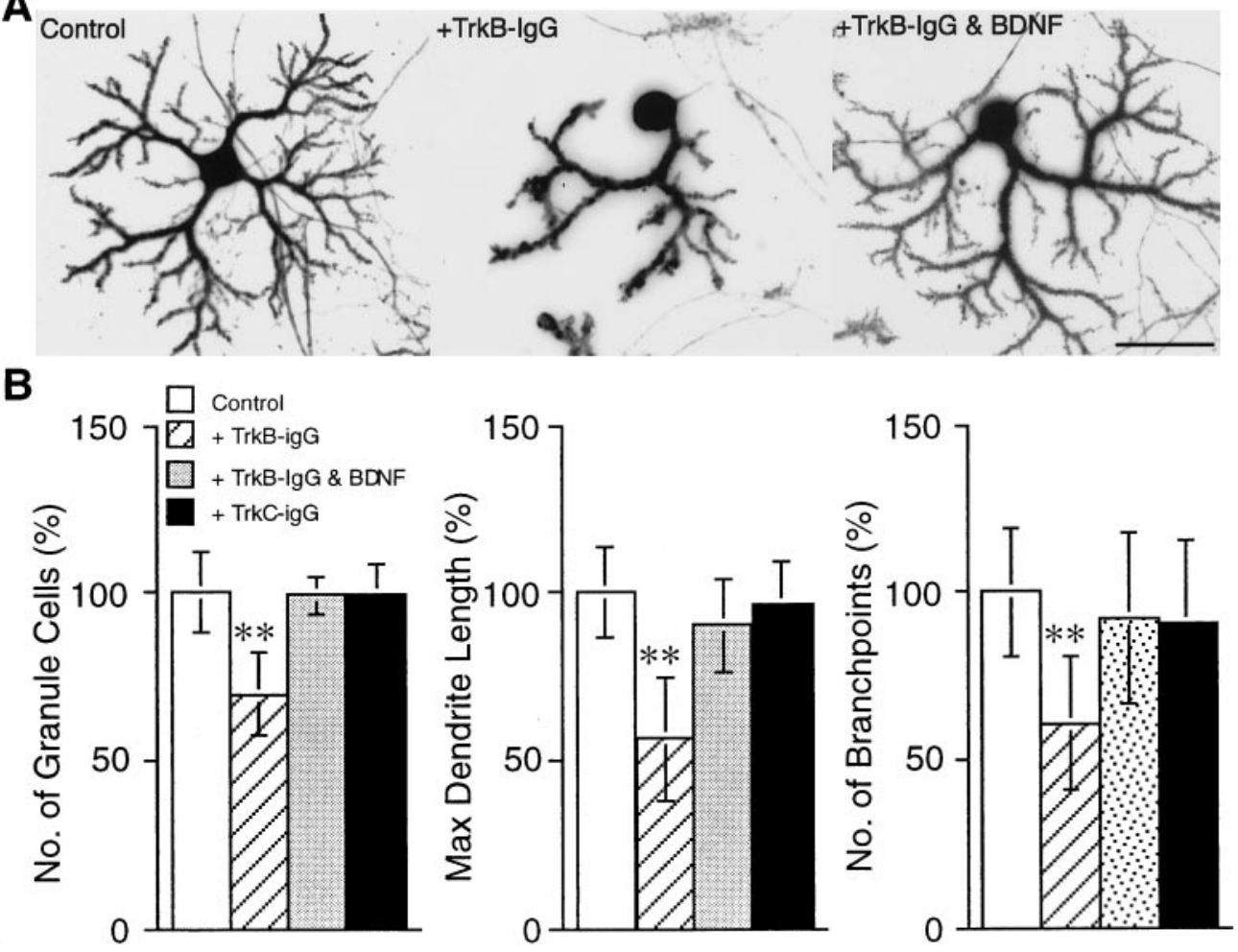

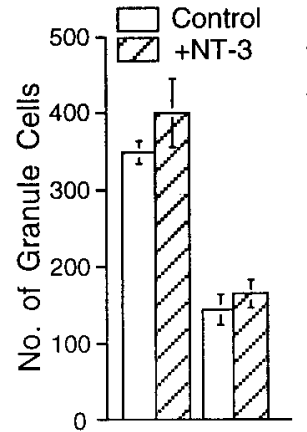

APV

$(-)$

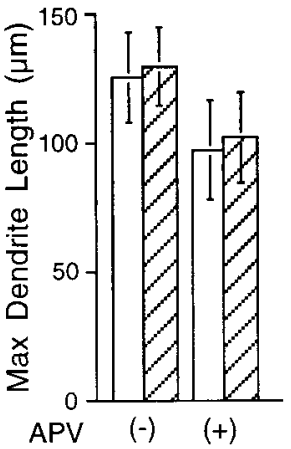

$(+)$

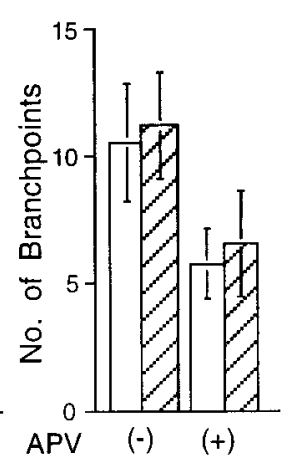

(+)

Figure 7. No significant effect of NT-3 on dendritic differentiation of Purkinje cell. Cerebellar neurons were cultured together with NT-3 (30 $\mathrm{ng} / \mathrm{ml}$ ) in the absence or presence of $100 \mu \mathrm{M}$ APV. The cells were fixed after 14 DIV and visualized by double immunostaining for calbindin D-28K and NSE. Graphs show the quantitative analysis of the effect of NT-3 on granule cell survival and Purkinje cell dendritic differentiation in the absence or presence of $100 \mu \mathrm{M}$ APV. No significant differences were seen in the granule cell survival rate, dendrite outgrowth, and the branching of Purkinje cells between the cultures treated with and without NT-3. Error bars indicate $\mathrm{SD}$.

ment. Electrophysiological recording of oligonucleotide-treated Purkinje cells showed that only antisense oligonucleotide could induce a reduction of NMDA responsiveness and that the sense oligonucleotide had no adverse effects. However, the reduction of the dendritic differentiation by the treatment with the antisense oligonucleotide was much smaller than that by the antisense oligonucleotide plus APV (Fig. 4B). These results suggest that NMDA receptors expressed by granule cells play the major role in the regulation of Purkinje cell dendritic differentiation.

\section{BDNF plays an important role in Purkinje cell differentiation}

In our study, the addition of BDNF to the control culture did not significantly affect the morphology of Purkinje cells but counteracted the inhibitory effects of APV on dendrite development of Purkinje cells (Fig. 5). In contrast, blockade of TrkB signaling by

the addition of TrkB-IgG caused significant perturbation of dendritic outgrowth and branching (Fig. 6). These results are apparently different from those of a previous study in which the addition of TrkB-IgG to Purkinje cells cocultured with granule cells had no apparent effect on the dendritic morphology of Purkinje cells (Shimada et al., 1998). The explanation for this discrepancy is probably to be found in the culture medium. In the present study, we used a medium based on DMEM-F12 without the addition of any neurotrophic factors (Furuya et al., 1998) enhancing the survival of granule and Purkinje cells. Other groups used a serum-free medium based on Basal Medium Eagle's (Schilling et al., 1991; Baptista et al., 1994; Lärkfors et al., 1996; Yuzaki et al., 1996) or serum-containing media based on Minimum Essential Medium (Cohen-Cory et al., 1991; Mount et al., 1994). Purkinje cells cultured using these media displayed relatively short dendrites and delayed maturation. These observations suggest that, in our culture system, the amount of substances necessary for the development of granule and Purkinje cells is sufficient and balanced or that neurotrophin receptors such as Trk and p75 are efficiently expressed, resulting in highly differentiated dendritic branches similar to those of cells grown in vivo. Under this condition, BDNF is indispensable, but the effect is presumably saturated, because addition of exogenous BDNF caused no further differentiation of the Purkinje dendrites. In contrast, in other cultivation methods, substances and corresponding receptors essential for the development of cerebellar neurons are thought to be lacking and/or imbalanced; expression of TrkB might be suppressed. Under such condition, it is presumed that modulation of TrkB signaling alone by exogenously applied BDNF or TrkB-IgG would cause no significant alteration of Purkinje cell differentiation. Indeed, our results shown in Figure 5 are consistent with an in vivo study, using BDNF gene-deficient mice in which granule cells exhibited decreased survival rate concomitant with stunted growth of Purkinje dendrites (Schwartz et al., 1997).

\section{Signaling via AMPA receptors and metabotropic glutamate receptors contributes to dendritic branching of Purkinje cells}

The present results suggest that some factors provided by the granule cells regulate Purkinje cell differentiation, in agreement 

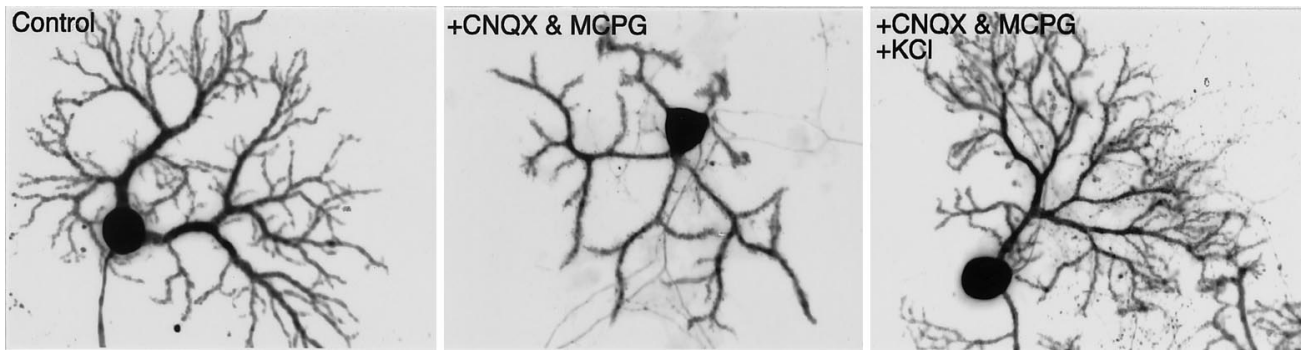

Figure 8. The effect of glutamate receptor activation on dendritic differentiation of Purkinje cell. Purkinje cells were cultured in the absence (left) or presence (middle) of $10 \mu \mathrm{M}$ CNQX and $1 \mathrm{mM} \mathrm{MCPG}$ for $14 \mathrm{~d}$, followed by fixing and double immunostaining for calbindin D-28K and NSE. The Purkinje cell in the right was cultured with similar concentrations of CNQX and MCPG in a high-potassium-containing medium (20 mM). Scale bar, $50 \mu \mathrm{m}$. Quantitative analysis of the dendritic differentiation is shown in Table 1.

with previous reports (Baptista et al., 1994; Doughty et al., 1999). As the neurotransmitter at synapse between granule cells and Purkinje cells, glutamate could play a role in the dendritic differentiation of Purkinje cells. Results of this study showed that the branching and thickening of the dendrites were impaired when both AMPA-type and metabotropic glutamate receptors were blocked and that these effects were reversed by increasing the concentration of $\mathrm{KCl}$ in the culture medium. Because both AMPAtype and metabotropic glutamate receptor stimulation can induce an increase in $\left[\mathrm{Ca}^{2+}\right] \mathrm{i}$, we suggest that elevation of $\left[\mathrm{Ca}^{2+}\right]_{\mathrm{i}}$ after electrical activity is critical for dendritic branching and thickening of Purkinje cells. This notion is consistent with the results of a previous study (Schilling et al., 1991), which showed that the emergence of electrical activity in Purkinje cells (7-9 DIV) was coincident with the initiation of dendritic branching (7-9 DIV). In these studies, cultured Purkinje cells were treated with TTX to reduce synaptic activity, resulting in the marked decrease in dendritic branching of Purkinje cells. We also performed similar experiments using TTX and obtained similar results, including a decrease in the granule cell survival rate (data not shown). However, the dendrites in TTX-treated Purkinje cells in our and other group's experiments did not exhibit spine structures (data not shown) (Schilling et al., 1991), whereas dendrites of Purkinje cells treated with glutamate receptor antagonists exhibited mature spines, which are apparent even by fluorescence microscopy (Fig. $8)$. This discrepancy is presumed to originate from the difference in the sites for action between TTX and the glutamate receptor antagonists. TTX, in addition to electrical activity, blocks activitydependent release of substances from granule cells such as neurotrophins, whereas the AMPA-type and metabotropic glutamate receptor antagonists (but not the NMDA receptor antagonist) have a relatively negligible effect on the activity-dependent release from granule cells. Therefore, it is suggested that TTX blocked the release of a substance required for the development of spines. The nature of this substance should be investigated in future studies.

A recent in vivo work showed contradictory results; the spinogenesis on the proximal dendrites was facilitated by TTX application (Bravin et al., 1999). The discrepancy is considered to be attributable to several reasons. First, because in in vivo experiments adult animals were used, mature spines are probably resistant to TTX treatment, whereas spinogenesis in developing neurons is easily affected. Second, under in vivo condition, Purkinje cells are surrounded by numerous non-neuronal cells that may release some neurotrophic factors sufficient for the spinogenesis on Purkinje dendrites independent of any electrical activity. Third, signals through climbing fibers, which are absent in cultured Purkinje cells, have repressive action on the spine formation (Bravin et al., 1999). Hence, it is considered that inhibition of climbing fiber activity in vivo by TTX eliminated this repressive effect, consequently allowing spine formation on dendrites.

In the present study, we show that granule cells initiate and support the dendritic differentiation of Purkinje cells when NMDA receptors on granule cells are activated. The electrical activity, followed by the increase of $\left[\mathrm{Ca}^{2+}\right]_{\mathrm{i}}$ in Purkinje dendrites, is thought to play an important role in branching and thickening of the dendrites, whereas in the case of dendritic spine formation, at least in culture, other factors released from the granule cell axon terminals seem to be essential. Only the coordination of these different stimuli would elaborate the well differentiated dendritic arbor of Purkinje cells.

\section{REFERENCES}

Akazawa C, Shigemoto R, Bessho Y, Nakanishi S, Mizuno N (1994) Differential expression of five $N$-methyl-D-aspartate receptor subunit mRNAs in the cerebellum of developing and adult rats. J Comp Neurol 347:150-160.

Balázs R, Hack N, Jorgensen OS, Cotman CW (1989) N-methyl-Daspartate promotes the survival of cerebellar granule cells: pharmacological characterization. Neurosci Lett 101:241-246.

Baptista CA, Hatten ME, Blazeski R, Mason CA (1994) Cell-cell interactions influence survival and differentiation of purified Purkinje cells in vitro. Neuron 12:243-260.

Bravin M, Morando L, Vercelli A, Rossi F, Strata P (1999) Control of spine formation by electrical activity in the adult rat cerebellum. Proc Natl Acad Sci USA 96:1704-1709.

Burgoyne RD, Graham ME, Cambray-Deakin M (1993) Neurotrophic effects of NMDA receptor activation on developing cerebellar granule cells. J Neurocytol 22:689-695.

Chao MV (1992) Neurotrophin receptors: a window into neuronal differentiation. Neuron 9:583-593.

Cohen-Cory S, Dreyfus CF, Black IB (1991) NGF and excitatory neurotransmitters regulate survival and morphogenesis of cultured cerebellar Purkinje cells. J Neurosci 11:462-471.

Doughty ML, Lohof A, Selimi F, Delhaye-Bouchaud N, Mariani J (1999) Afferent-target cell interactions in the cerebellum: negative effect of granule cells on Purkinje cell development in lurcher mice. J Neurosci 19:3448-3456.

Favaron M, Manev RM, Rimland JM, Candeo P, Beccaro M, Manev H (1993) NMDA-stimulated expression of BDNF mRNA in cultured cerebellar granule neurons. NeuroReport 4:1171-1174.

Furuya S, Makino A, Hirabayashi Y (1998) An improved method for culturing cerebellar Purkinje cells with differentiated dendrites under a mixed monolayer setting. Brain Res Brain Res Protoc 3:192-198.

Gallo V, Kingsbury A, Balazs R, Jorgensen OS (1987) The role of depolarization in the survival and differentiation of cerebellar granule cells in culture. J Neurosci 7:2203-2213.

Gao WQ, Zheng JL, Karihaloo M (1995) Neurotrophin-4/5 (NT-4/5) and brain-derived neurotrophic factor (BDNF) act at later stages of cerebellar granule cell differentiation. J Neurosci 15:2656-2667.

Gavin R, Stefano V (1999) Distinct synaptic and extrasynaptic NMDA receptors in developing cerebellar granule neurons. $J$ Neurosci 19:10603-10610.

Ghosh A, Carnahan J, Greenberg ME (1994) Requirement for BDNF in activity-dependent survival of cortical neurons. Science 263:1618-1623.

Ito M (1984) Cerebellar functions. In: The cerebellum and neural control, pp 353-465. New York: Raven.

Kilic G, Moran O, Cherubini E (1991) N-methyl-D-aspartate receptormediated spontaneous activity in cerebellar granule cells in culture. Neurosci Lett 130:263-266.

Lärkfors L, Lindsay RM, Alderson RF (1996) Characterization of the responses of Purkinje cells to neurotrophin treatment. J Neurochem 66:1362-1373

Laube B, Hirai H, Sturgess M, Betz H, Kuhse J (1997) Molecular determinants of agonist discrimination by NMDA receptor subunits: analysis of the glutamate binding site on the NR2B subunit. Neuron 18:493-503.

Lindholm D, Castren E, Tsoulfas P, Kolbeck R, Berzaghi MdP, Leingartner A, Heisenberg CP, Tessarollo L, Parada LF, Thoenen H (1993) Neurotrophin-3 induced by tri-iodothyronine in cerebellar granule cells promotes Purkinje cell differentiation. J Cell Biol 122:443-450. 
Marini AM, Rabin SJ, Lipsky RH, Mocchetti I (1998) Activity-dependent release of brain-derived neurotrophic factor underlies the neuroprotective effect of $N$-methyl-D-aspartate. J Biol Chem 273:29394-29399.

Momiyama A, Feldmeyer D, Cull-Candy SG (1996) Identification of a native low-conductance NMDA channel with reduced sensitivity to $\mathrm{Mg}^{2+}$ in rat central neurones. J Physiol (Lond) 494:479-492.

Moran J, Patel AJ (1989) Stimulation of the $N$-methyl-D-aspartate receptor promotes the biochemical differentiation of cerebellar granule neurons and not astrocytes. Brain Res 486:15-25.

Morrison ME, Mason CA (1998) Granule neuron regulation of Purkinje cell development: striking a balance between neurotrophin and glutamate signaling. J Neurosci 18:3563-3573.

Mount HT, Dreyfus CF, Black IB (1994) Neurotrophin-3 selectively increases cultured Purkinje cell survival. NeuroReport 5:2497-2500.

Myers KJ, Dean NM (2000) Sensible use of antisense: how to use oligonucleotides as research tools. Trends Pharmacol Sci 21:19-23.

Pfeiffer S, Leopold E, Schmidt K, Brunner F, Mayer B (1996) Inhibition of nitric oxide synthesis by $N^{\mathrm{G}}$-nitro-L-arginine methyl ester (L-NAME) requirement for bioactivation to the free acid, $N^{\mathrm{G}}$-nitro-L-arginine. $\mathrm{Br} \mathrm{J}$ Pharmacol 118:1433-1440.

Reitstetter R, Yool AJ (1998) Morphological consequences of altered calcium-dependent transmembrane signaling on the development of cultured cerebellar Purkinje neurons. Dev Brain Res 107:165-167.

Rocamora N, Garcia-Ladona FJ, Palacios JM, Mengod G (1993) Differential expression of brain-derived neurotrophic factor, neurotrophin-3, and low-affinity nerve growth factor receptor during the postnatal development of the rat cerebellar system. Mol Brain Res 17:1-8.

Rosenmund C, Legendre P, Westbrook GL (1992) Expression of NMDA channels on cerebellar Purkinje cells acutely dissociated from newborn rats. J Neurophysiol 68:1901-1905.

Schilling K, Dickinson MH, Connor JA, Morgan JI (1991) Electrical activity in cerebellar cultures determines Purkinje cell dendritic growth patterns. Neuron 7:891-902.
Schilling K, Schmidt HH, Baader SL (1994) Nitric oxide synthase expression reveals compartments of cerebellar granule cells and suggests a role for mossy fibers in their development. Neuroscience 59:893-903.

Schwartz PM, Borghesani PR, Levy RL, Pomeroy SL, Segal RA (1997) Abnormal cerebellar development and foliation in BDNF-/- mice reveals a role for neurotrophins in CNS patterning. Neuron 19:269-281.

Segal RA, Takahashi H, McKay RD (1992) Changes in neurotrophin responsiveness during the development of cerebellar granule neurons. Neuron 9:1041-1052.

Segal RA, Pomeroy SL, Stiles CD (1995) Axonal growth and fasciculation linked to differential expression of BDNF and NT3 receptors in developing cerebellar granule cells. J Neurosci 15:4970-4981.

Shimada A, Mason CA, Morrison ME (1998) TrkB signaling modulates spine density and morphology independent of dendrite structure in cultured neonatal Purkinje cells. J Neurosci 18:8559-8570.

Snider WD, Lichtman JW (1996) Are neurotrophins synaptotrophins? Mol Cell Neurosci 7:433-442.

Southam E, East SJ, Garthwaite J (1991) Excitatory amino acid receptors coupled to the nitric oxide/cyclic GMP pathway in rat cerebellum during development. J Neurochem 56:2072-2081.

Spitzer NC (1994) Spontaneous $\mathrm{Ca}^{2+}$ spikes and waves in embryonic neurons: signaling systems for differentiation. Trends Neurosci 17:115-118.

Velier JJ, Ellison JA, Fisher RS, Vinters HV (1997) The trkC receptor is transiently localized to Purkinje cell dendrites during outgrowth and maturation in the rat. J Neurosci Res 50:649-656.

Viani P, Giussani P, Riboni L, Bassi R, Tettamanti G (1997) Behaviour of nitric oxide synthase in rat cerebellar granule cells differentiating in culture. FEBS Lett 408:131-134.

Yuzaki M, Forrest D, Verselis LM, Sun SC, Curran T, Connor JA (1996) Functional NMDA receptors are transiently active and support the survival of Purkinje cells in culture. J Neurosci 16:4651-4661. 